\title{
Is the Appointee Procedure a Real Selection or a Mere Political Exchange? The Case of the Italian Health-Care Chief Executive Officers
}

\section{ABSTRACT}

One of the central aspects of the Italian health-care reform deals with the new position of a chief executive officer (CEO) selected through an appointment procedure. By drawing data from 164 Curriculum Vitae (CVs), a cluster analysis was carried out to investigate the typologies of CEOs that were selected and assess them by comparing their educational and professional characteristics. Three different categories of CEOs are defined and ranked: (i) "experienced CEO", with the highest inter-organizational mobility and the highest number of triad-assignments; (ii) "experienced local directors", with a better cultural background, medium mobility and medium number of triad assignments; and (iii) "business like professionals" with the lowest professional and educational profile. How these typologies are distributed over the Italian regions gathered in groups were then verified, considering the kind of organizational arrangements in the local appointment procedures. Finally, the overall results of the CEOs selection system in health-care lead to suboptimal appointments: when the organizational arrangements are better employed, they totally exclude the selection of the lowest category. On the contrary, when organizational arrangements are wrongly employed the first category decreases where the second increases.

\section{KEY-WORDS}

HEALTHCARE REFORM, CEO, APPOINTMENT PROCEDURES 


\section{Introduction}

Over the last two decades, the centralised health policy system in Italy has transitioned to a system characterised by a devolution of control to the regional level. Moreover, the organization of health-care across large parts of Europe have undergone major changes that have marked a change of emphasis from a professionally driven service to a managerially driven one. Today, the current Italian health system reflects the features of these two institutional reforms.

The Reform Law of the 1990s (59/1997 law as amended), which introduced decentralisation to the Italian National Health Service (INHS), addressed a political, fiscal and organizational devolution with the aim of making regions more responsible for the funding, organising and delivering of health services in their own territories. Decentralisation was paralleled by a process of "managerialisation". It stemmed from the international New Public Management (NPM) movement, whose basic principles include the introduction of professionalism, competition and private sector styles of management into the public sector, with it being considered crucial for improving the effectiveness and efficiency of public service delivery and governmental performance in general (Hood, 1991).

One of the central aspects of the health-care reform considers the leading roles. The traditional management committees were replaced by a single executive post covered by a high-status chief executive officer (CEO). The idea was to concentrate all the executive power into one post. "This was claimed both to speed up any decision-making procedures as well as ensure greater transparency since only one person was responsible and accountable for performance” (Mattei, 2006: 1015). Furthermore, in accordance with the principles of devolution, the regional executive (namely, the President) had exclusive competence in his/her choice through an appointment procedure. The CEO is the highest manager of the health service structures and has appointment authority over the two top directors who are directly responsible to him, i.e., the financial and clinical directors. According to national law (Legislative Decree 502/1992), this triad of top managers defines the governance of the single health-care structure under the CEO's leadership. In the institutional framework, the CEO seems to be a (top) connecting figure between politics and the administration. Their selection depends on a regional executive who offers and renews their private contracts, with their remuneration depending on the achievement of managerial objectives.

Several theoretical arguments have been developed to explore the question of whether the appointment procedure for CEOs leads to more or less effectiveness and efficiency in the health system. There is no clear conclusion from current literature, with competing theories providing arguments both for and against this role. While some argue that it is the appointment procedure itself that weakens its role because of the direct political control (Page and Wright, 1999) that could escalate with mere partisan choices, others claim that the presence of decentralised government institutions can be considered a favourable context for the implementation of the logic of NPM local decisions that include hiring procedures (Christensen, Laegreid and Wise, 2000).

This preliminary analysis tries to answer the above questions by moving from a theoretical 
debate about the appointment procedure to an empirical analysis linked to their practical results. Since the selection of a CEO is a President's direct choice among single top managers, CEOs information was collected from their CVs. Starting with the CEOs' characteristics, the aim was to understand if and under what circumstances the appointment procedure was a suitable tool for selecting competitive high management. The choice to focus on CVs is in line with the International Civil Service Effectiveness (InCiSE) Index related to "human resource management", which mainly measures the extent to which civil service recruitment systems are effective in attracting and retaining talent based on the level of education, linguistics and mathematical competence, along with previous professional experience. The results show that in spite of the two abovementioned reforms, this mechanism is still completely disconnected in Italy, which is positioned in the last place among OECD countries. The indicator is limited to the bureaucratic management. In this sense, the analysis is extended to a case of political management reproducing the same criterion. In contrast to the theoretical debate on the point, in this study, the appointment procedure is not by itself effective or ineffective in selecting the "right" people. It is both the occurrence of some organizational arrangements and its actual use that makes the access channel effective or ineffective.

Thus, the research questions are the following. Considering their characteristics, what typologies of CEOs have been selected in the INHS? Is there a rank emerging in comparing the typologies? Finally, how are the typologies locally distributed considering the procedures on the basis of their organizational arrangements?

The paper is organised as follows. First, the current literature on the institutional reforms and INHS is reviewed, focusing on their unexpected effects and possible impacts on CEO selection. Then, the data used in the analysis and the chosen methodological approach are described, with the main findings being presented. The final section discusses the significance of the findings for the theory and practice as well as any possibilities for future research.

\section{The institutional reform and the transition in the Italian national health-care system}

\section{1 "Decentralisation" and "managerialisation" in health-care system}

The case of Italy is particularly interesting because its NHS was significantly influenced by the model of the UK NHS (Dent, 2005). However, virtually since its inception, it has been subjected to the strong forces of decentralisation and their demands for local autonomy. While the central government continues to influence core funding and service guidelines, many competencies have been transferred from the centre to the local sub-governments. The Italian regions have responsibility for both the allocation of funds as well as the organization and administration of local health services. With respect to their financing, the regions access a central pot of resources named National Health Fund (Fondo Sanitario Nazionale - FSN), which is determined by a weighted capitation formula, but they can also allocate their own resources from local taxation. More specifically, for the aim of 
this study, the regions have the power to determine the governance model of health-care services; establish and clarify the strategies and objectives needed to implement them; and as previously mentioned, appoint, evaluate and (if necessary) fire the CEO's health-care structures (Tediosi, Gabriele and Longo, 2009).

Furthermore, decentralisation was paralleled by a process of "managerialisation". Its principles became the foundation for the whole public sector and for the health service, in particular, by addressing matters such as the organization and rationalisation of resources and the use of market mechanisms (Anessi-Pessina and Cantù, 2006).

The combination of these institutional processes gave rise to an entrepreneurial model based on modern management practices that were tried and tested in the private sector and applied to the provision of care. An early reform in 1992-1993 reduced the number of local health providers from approximately 660 to approximately 200 local health enterprises (Aziende Sanitarie Locali). Furthermore, it provided approximately 100 public hospitals with the opportunity to be converted into semi-independent hospitals (Aziende Ospedaliere). The aim of this re-organization was to introduce greater competition into the SSN and present possibilities for the entry of private providers (Jommi, Cantù and Anessi-Pessina, 2001). Small-scale autonomous sanitary enterprises (Aziende Sanitarie) provided care for the local population either on their own premises or in institutions bound by contractual agreements (Simonet, 2008).

This re-structuring went hand-in-hand with attempts to strengthen the management capabilities of Italian public hospitals. As a consequence, health-care top management has witnessed a significant transformation from the old bureaucratic public model to a new and more business-like one. As mentioned above, the traditional management committees have been replaced with the CEOs single executive post.

If devolution gives the regional President the exclusive competence in selecting CEOs, NPM has led to the private nature of their contract that is limited in time and conditioned to the achievement of the managerial objectives. These objectives are concurrently financial and organizational, with them being oriented to the common purpose of containing expenditures without prejudice for the quality of the services.

\subsection{The unexpected effects of the reforms and their possible impact on the selection of CEOs}

As for every institutional reform, achievements do not come without shortcomings.

First, according to the InCiSE report (InCiSE, 2017), the reforms did not have the expected results. Using a scale from 0 to 100 to grade the technological frontiers in public administrations based on regulations, human resources, incentives, public services and the transparency of decision processes, Italy is ranked 20. The average of advanced economies is 60. As previously stated, one of the lowest indicators refers to the quality of human resources in the Italian public administration.

Second, studies have increasingly highlighted the paradoxes and the dangers of managerialism and of the devolution (Maor, 1999; Hood, 2000; Hood and Peters, 2004; Henderson et al., 2013). 
The most relevant to the aim of this study identifies an institutional weakness of the reform in the increase in local autonomy. This represents support for the emergence of a clientelist and uncontrollable local management, given that a legal vacuum in the devolution does not provide any kind of coordination or integration among the different levels of government. More specifically, it has been argued that the regional political cultures have been compromised by a ubiquitous "partisan pressure and manipulation" that has emerged together with the local autonomy in the management of the resources (Putnam, 1993; Saraceno and Negri, 1994). For the organization of the Italian health-care system on the local level, studies have underlined that it would have been equally plagued with partitocrazia (i.e., political clientelism), which is described as, "rule by [political] parties". "All elements of life are politicised, and every person must belong to a political party, and have a sponsor, in order to succeed" (Dent 2005: 626). Clientelism and party affiliation would survive as an important characteristic of health-care organization and delivery, despite any rationalising force of NPM (Maor, 1999).

As Sundell (2012) argues, there is a trade-off between the traditional civil selection systems of public servants and the private-like selection processes that have been used following the institutional reforms. In his work, Sundell shows how these two forms of selection can be enforced to give the best results and avoid patronage bias. It is the degree of patronage that indicates the best selection system to adopt. A high degree of patronage requires the use of merit-based selection procedures that are the traditional, centralised and formal examinations. Conversely, a low degree of patronage and the presence of efficient accountability, exposure and sanction rules can allow for the adoption of private-like selections based on a fiduciary bound between the political chief and the appointed manager. In this scenario, the CEO appointment procedure could represent a circumstance to dispense jobs in return for political favours, instead of a selection procedure that is effective in attracting competitive resources.

In addition to the selection ${ }^{1}$, it is the exclusive duty of the regional President to evaluate the performance and renew the contract of the CEO. CEOs can have their positions confirmed by achieving yearly objectives that are usually linked to the economic performance of their firm. They are subject to an annual evaluation based on the results achieved where the supervisory role and annual evaluations were performed directly by the Regional President (Baroni, 2004). It seems that the question of whether the CEO appointment procedure could be an effective way to attract high management or it could turn into a high patronage tool with the aim of enhancing the clientelism could require a change in perspective: starting with the CEO's professional characteristics rather than the theoretical effectiveness of the selection tool. By reading their CVs, an attempt has been made to understand who they are and what professional characteristics they share. By gathering the CEOs' profiles, three typologies have been identified along with the related distinguishing criteria.

\footnotetext{
The President of the Region appoints the CEO by choosing from a national list of candidates created by an ad hoc committee of experts and senior civil servants at the Ministry of Health. The decree does not specify the conditions for inclusion on the list (Legislative Decree 502/92).
} 
Finally, the nature of the local appointment procedures has been examined, investigating whether they provided two essential organizational arrangements: (i) the transparency of the process; and (ii) the existence of a job description with specific educational/professional requirements. Theoretically, (Sancino, Sicilia and Grossi, 2017) the more such organizational arrangements are able to constrain political discretion, the more appointments are likely to realize the potential benefits that they are expected to offer. It could be particularly true in a case like this where the lack of clear requirements in the national laws should be compensated with the existence of clear standards on a regional basis. Furthermore, the distribution of the three categories on the basis of the procedures could represent a way to check how the local institutions try to cope with the new reform and, at the same time, assess their choices.

\section{The empirical analysis}

\subsection{Data}

This section describes the data used for the analysis. Data was collected from $164 \mathrm{CVs}$ of as many CEOs. The CEOs' CVs can be found in a specific section in every local health-care firm website. The number of sample cases was lowered to 159 after the list-wise case deletion of five statistical units that had missing data. A list of health-care structures ${ }^{2}$ that is available on the Italian Health Ministry website was used to lead the extraction of cases. The variables that were drawn from the CVs and that composed the dataset come from four main groups of characteristics.

1. Professional career. The following variables were considered: the overall number of assignments (in one of the triad positions), the number of managerial assignments (different from triadassignments) in public health-care firms, and the number of managerial assignments held within private structures. In particular, with regard to CEOs mobility, the number of assignments in different health-care firms (which refers to the number of times the CEO has moved from one work place to another) was checked to define an overall mobility indicator. The number of assignments (triads) in different structures (high overall mobility) has been proved to improve CEO's skills (Sørensen, 1999). The number of teaching positions in accredited training courses, the number of publications, and the number of conferences were also considered.

\footnotetext{
2 The list includes all kinds of structures that constitute local healthcare firms. Three kinds of healthcare structures were considered since they represent $85 \%$ of the health public structures: "Hospital" (Azienda Ospedaliera), "Hospital integrated with University" (Azienda ospedaliera integrata con l'università), "Directly managed Unit-Hospital" (Ospedale a gestione diretta). The first and second kinds of structures have their own CEO. The third is usually the largest unit of a group of hospitals that constitutes a unique local healthcare firm with a common CEO. The excluded types of structures are accredited private structures and Universities, with it being due to the significant differences between the careers of their CEOs and the CEOs who are at the top of public healthcare firms.
} 
2. Reference career area. Different from the overall mobility indicator, in this case, the number of triad-assignments in a "mode-region", the number of triad-assignments outside the moderegion, and the ratio between this last variable and the overall number of triad-assignments to identify a degree of out-of-region mobility were all considered.

3. Post-degree courses. The idea was to check the number of postgraduate training "extras". By excluding those that are compulsory parts of the national list, further postgraduate academic courses were considered.

4. Demographical and political data. The gender and age of the CEOs, healthcare structures distributed among three Italian macro-regions and the political orientation of the regional governments were all collected.

CVs were used as data source since, according to the law (Legislative Decree 502/92), the $\mathrm{CV}$ is the document under assessment during the whole procedure. CV must be included in the national list, the CV must be included in the case of further regional short list (where provided in the regional laws), the $\mathrm{CV}$ must be sent to a regional commission that preselects the candidates in the early phases of the local selection procedure, and the Presidents' choice relies on the CV. Moreover, some studies (Sandström, 2009; Cañibano and Bozeman, 2009) proved the effectiveness of using CVs as data sources in research. Even if they focused mainly on samples representative of researchers, the authors showed that CVs can be efficiently used to construe professional profiles. A large part of the biases that CVs raise can be avoided by using complementary sources, such as institutional websites and online newspapers. In this study, more than one CV per CEO had to be collected so as to reduce missing data as much as possible. Furthermore, some missing data, such as the final mark received in a degree program, were impossible to collect. Such a high amount of missing data related to the final mark of the degree can be considered as a voluntary omission (Tables A and B in the appendix show, respectively, the final mark of the degree in percentage terms and the gender with the age in the whole sample and in the clusters). As a consequence, it was decided to replace this variable with the number of postgraduate degrees and use it in the analysis.

Since CVs reflect professional careers, which are, by definition, a unique history for every single CEO, it was decided not to delete any cases that showed outliers. The presence of outliers is particularly marked for variables such as academic publications, and is highlighted when the standard deviations are higher than the mean values. Deleting those cases would have provided an incorrect representation of the CEOs' careers.

The sample shows a remarkable difference between women (15.72\% of total observations) and men $(84.28 \%)$. The average age of a CEO is 58 years $(\mathrm{sd}=5.34)$. The geographical distribution of CEOs shows that those who lead the Northern health-care structures $(50.31 \%, \mathrm{n}=80)$ outnumber both those in the South $(33.96 \%, n=54)$ and in the Central Italy $(15.72 \%, n=25)$. This distribution

\footnotetext{
3 The "mode-region" is the region with the highest frequency of top-managerial assignments for a CEO. The statistical mode was used to indicate the region in which the CEO had his/her highest number of assignments in the triad.
} 
is very likely due to the recent process of the reorganization of Italian health-care firms. In most cases, the process is followed by a criterion of rationalisation. The main result has been the union of more local health-care firms. Furthermore, every regional government has reformed its health-care system by applying different degrees of this criterion. The differences in the number of structures among the macro-regions are also explained by the different political choices in terms of the reorganization of the regional health-care system. Finally, the President's political position was found to be leftwing in $70 \%$ of the cases.

The descriptive statistics of variables used to cluster CEOs are listed in Table 1. Reference was made to the mean values of variables in the clusters so that it was possible to obtain an overall representation of the characteristics of the sample.

Table 1. Mean values of variables in the whole sample $(n=159)$

\begin{tabular}{lcccc}
\hline Variables & mean & sd & min & max \\
\hline Number of top managerial assignments in the mode-region & 3.52 & 2.2 & 0 & 11 \\
\hline Number of top managerial assignments out of the mode-region & 0.30 & 0.82 & 0 & 5 \\
\hline $\begin{array}{l}\text { Out-of-region mobility } \\
\text { (ratio of top managerial assignments out of mode-region to the total of the } \\
\text { top managerial assignments) }\end{array}$ & 0.05 & 0.14 & 0 & 1 \\
\hline $\begin{array}{l}\text { Number of top managerial assignments } \\
\text { Number of managerial assignments } \\
\text { (other than CEO) }\end{array}$ & 3.81 & 2.40 & 1 & 12 \\
\hline $\begin{array}{l}\text { Number of private managerial assignments } \\
\text { Teaching positions }\end{array}$ & 2.65 & 2.38 & 0 & 12 \\
\hline $\begin{array}{l}\text { Publications } \\
\text { Conferences }\end{array}$ & 0.29 & 0.90 & 0 & 5 \\
\hline $\begin{array}{l}\text { Overall mobility } \\
\text { (number of CEOs' workplace changes) }\end{array}$ & 16.52 & 3.53 & 0 & 22 \\
\hline \begin{tabular}{l} 
Post-degree titles \\
\hline
\end{tabular} & 12.00 & 33.71 & 0 & 250 \\
\hline
\end{tabular}

Regarding the organizational arrangements in the local appointment procedures, data from the official documents available on the Regions' websites was taken, with the focus being two main aspects (i) the transparency of the process; and (ii) the existence of a job description with specific educational/professional requirements.

Transparency of the process is connected both with the concept of clarity and of openness. In the context of selection decisions, reference is made to the criteria in shortlisting (where provided under regional laws) and/or in the preselection as well as to the accessibility of the candidates' CVs. 
As for the job description of the position to be filled by public appointment, it was investigated whether there were specific educational background/training and/or some professional requirements to be satisfied for an applicant to be eligible for the appointment. As noted above, the way in which public appointments are locally managed could help to control how the local institutions contribute to implement NPM, if considering the lack of specific conditions to be included in the national list. Table 2 shows the main results. "No" is used when no criteria for the short lists or the preselection were found as well as when there were no other CVs apart from that of the selected CEO. "No" was also used when no job description or too generic criteria that left space for any kind of interpretation were found, thus making it impossible to carry out an objective comparison among the candidates. Finally, the regions were classified into four groups according to the occurrence of the organizational arrangements.

Table 2. Organizational arrangements in appointment procedures

\begin{tabular}{|c|c|c|c|c|}
\hline Regions & $\begin{array}{c}\text { Transparency in short lists } \\
\text { and/or in preselection }\end{array}$ & $\begin{array}{l}\text { Transparency in } \\
\text { candidates' CVs }\end{array}$ & $\begin{array}{c}\text { Job } \\
\text { description }\end{array}$ & Groups \\
\hline Abruzzo & No & No & No & 4 \\
\hline Basilicata & No & No & No & 4 \\
\hline Calabria & No & No & No & 4 \\
\hline Campania & Yes & Yes & No & 2 \\
\hline Emilia-Romagna & Yes & Yes & Yes & 1 \\
\hline Friuli-V. Giulia & Yes & Yes & No & 2 \\
\hline Lazio & Yes & No & No & 3 \\
\hline Liguria & Yes & Yes & Yes & 1 \\
\hline Lombardia & Yes & Yes & No & 2 \\
\hline Marche & Yes & Yes & Yes & 1 \\
\hline Molise & No & Yes & No & 3 \\
\hline Piemonte & Yes & No & Yes & 2 \\
\hline Puglia & Yes & No & No & 3 \\
\hline Sardegna & Yes & No & Yes & 2 \\
\hline Sicilia & Yes & Yes & No & 2 \\
\hline Toscana & Yes & Yes & Yes & 1 \\
\hline Trentino-A. Adige/Südtirol & Yes & Yes & No & 2 \\
\hline Umbria & Yes & No & No & 3 \\
\hline Valle d'Aosta & No & No & No & 4 \\
\hline Veneto & No & Yes & No & 3 \\
\hline
\end{tabular}




\subsection{Method and results}

The first research question is about the typologies of CEOs that can be identified by considering their characteristics. Thus, a cluster analysis was carried out by using variables selected from the list described above. Clusters were obtained by considering the elements that were directly drawn by CVs. For the professional career category, all the variables were selected. However, the variables in the reference career area were excluded from the cluster formation process due to their linkage to the overall number of triad-assignments. It was preferred to use the variables in this category as the descriptive elements of the clusters. For the post-degree courses category, the number of postgraduate degrees was also included in the set of variables that led the clustering process. Finally, the variables in the fourth category (demographical and political elements) were strictly used to describe and assess the clustering results. The set of variables that led the clustering process can be defined as a mix of professional experience and educational elements.

A hierarchical cluster analysis was carried out by adopting Ward's minimum-variance criterion (Ward, 1963). The software used for the data analysis was R-project. After standardising the selected variables, a classical Euclidean distances matrix was obtained. Ward's method produces the clusters by selecting the cases with the minimum squared distance, and it is based on a matrix of squared Euclidean distances that were provided to the software. This method was chosen to obtain the homogenous cases inside the clusters and the heterogeneous clusters. The choice of Ward's method was reinforced by the results obtained by using different clustering algorithms: the average distance was tested with complete and single linkage methods but the result showed too many overlaps between the clusters in terms of similarities of cases included in each cluster. The resulting clusters from using Ward's method were also the clearest from a graphical point of view, with the clusters seeming to be identifiable by their specific characteristics.

The dendrogram (Figure 1) was separated at different distance levels to obtain clusters that would be sufficiently distinct from each other. The CEOs' characteristics used to overlap when clustered for distance levels that produced more or fewer than three clusters. The choice of the best number of clusters is one of the most difficult problems in this kind of analysis. In this case, it was decided to balance a criterion of efficient separation between the final clusters and a criterion of preservation of the original information. The criterion is that clusters are efficiently and sufficiently separated when it is possible to identify specific characteristics for each cluster in terms of the means of the variables used in discriminating the cases. In fact, every result obtained was assessed by cutting the dendrogram at different distance levels: all the classifications with more than three and the one with only two clusters showed to contain too many similar cases. The following dendrogram shows the results of the cluster analysis. 
Figure 1. Cluster analysis results: CEOs in Italian healthcare firms

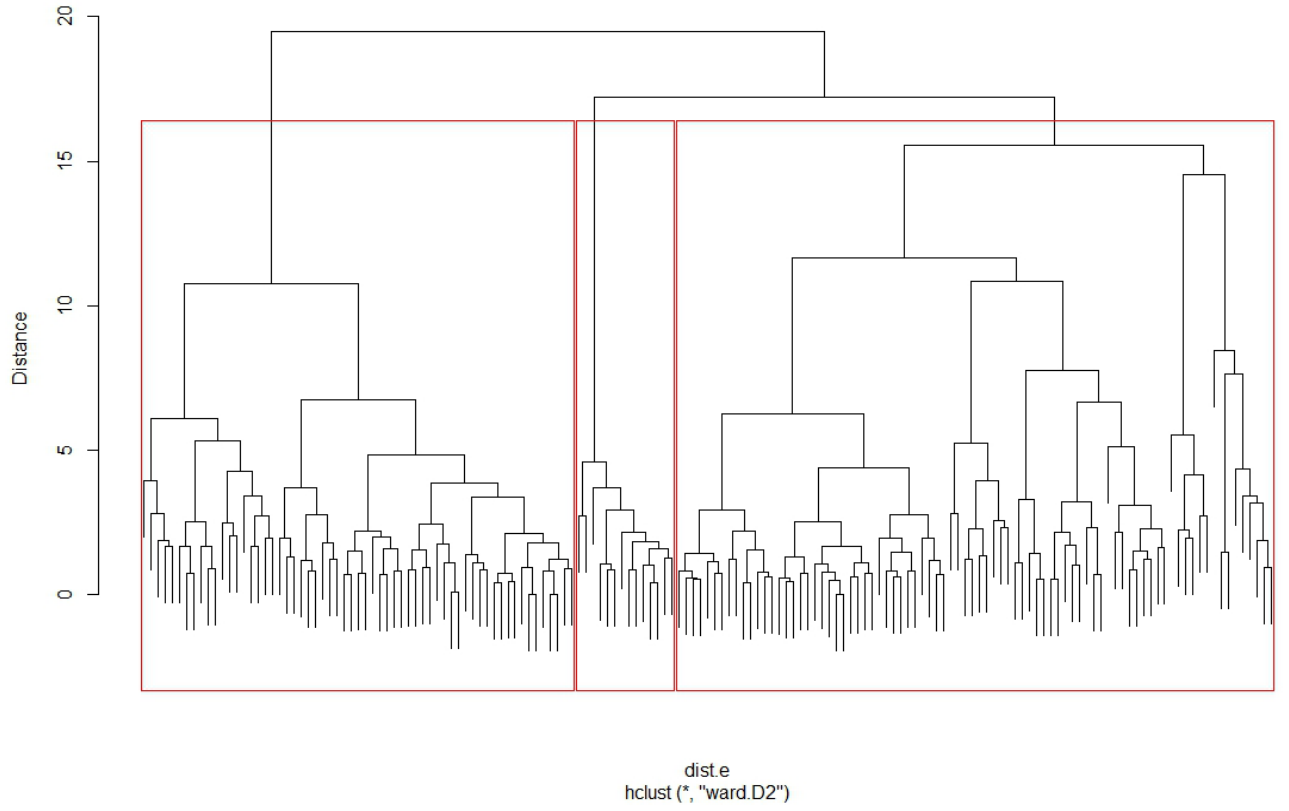

Note: R software output of the cluster analysis obtained by using the R package "stats". A hierarchical cluster analysis was chosen rather than non-hierarchical procedures since the aim is to determine the existence of different kinds of CEOs in an explorative way. Hierarchical clustering has allowed exploring all the possible kinds of classifications of the cases without setting any restriction to the process such as a fixed number of clusters. The internal difference in terms of squared distances is minimized by the agglomerating criterion so that the distance between the final cluster is maximized. In fact, the use of Ward's criterion provides that clusters that are internally more compact are also as far apart as possible. The dendrogram shows the merge procedure by the agglomeration in the clusters of cases by following Ward's method. The three clusters are highlighted by red rectangles.

The first and the third clusters are numerically higher (with respectively 61 and 84 observations) than the second cluster which contains few observations $(n=14)$, however the third cluster gathers CEOs whose characteristics are significantly different from the others' characteristics.

The mean values of variables for the three clusters are reported in Table 3. The eight variables used as clustering criteria are highlighted. The remaining four variables in the table provide a better representation of the differences between clusters. The difference between the mean values of the variables used in the agglomeration process represents another way to assess the distances ${ }^{4}$ between the three clusters.

The results show differences only with regard to specific characteristics of the CEOs, but this does not imply that they are approximate. Some characteristics tend to be homogeneous due to the

4 Distances between final clusters in this analysis were computed by taking in account both the distances between cluster's centres and width. The distances are the following: (2.4264) between clusters 1 and 2, (0.7170) between clusters 1 and 3 and (1.6246) between clusters 2 and 3. The distances computed are Euclidean distances. 
peculiar recruitment system of the CEOs in the Italian Health-care System that provides minimum requirements for eligibility for the national list. Those that show marked differences can identify the type of CEO in the cluster.

Table 3. Variables' mean values in the three clusters

\begin{tabular}{|c|c|c|c|c|c|c|}
\hline \multirow{2}{*}{$\begin{array}{l}\text { Clusters } \\
\text { Variables }\end{array}$} & \multicolumn{2}{|c|}{$1(n=61)$} & \multicolumn{2}{|c|}{$2(n=14)$} & \multicolumn{2}{|c|}{$3(n=84)$} \\
\hline & mean & sd & mean & sd & mean & Sd \\
\hline $\begin{array}{l}\text { Number of top managerial assignments in the } \\
\text { mode-region }\end{array}$ & 5.30 & 2.19 & 1.71 & 0.91 & 2.52 & 1.29 \\
\hline $\begin{array}{l}\text { Number of top managerial assignments out of the } \\
\text { mode-region }\end{array}$ & 0.59 & 1.16 & 0.43 & 0.94 & 0.06 & 0.24 \\
\hline $\begin{array}{l}\text { Out-of-region mobility } \\
\text { (ratio of triad assignments out of mode-region to the total } \\
\text { of the triad assignments) }\end{array}$ & 0.06 & 0.14 & 0.12 & 0.28 & 0.03 & 0.10 \\
\hline Number of triad assignments & 5.89 & 2.27 & 2.14 & 1.29 & 2.58 & 1.34 \\
\hline $\begin{array}{l}\text { Number of managerial assignments } \\
\text { (other than from the triad) }\end{array}$ & 1.92 & 1.73 & 3.36 & 1.34 & 3.06 & 2.77 \\
\hline Number of private managerial assignments & 0.03 & 0.18 & 3.00 & 0.88 & 0.02 & 0.15 \\
\hline Teaching positions & 2.18 & 2.77 & 1.00 & 1.47 & 3.01 & 4.14 \\
\hline Publications & 5.80 & 9.67 & 1.86 & 5.11 & 27.10 & 60.89 \\
\hline Conferences & 4.11 & 10.61 & 0.07 & 0.27 & 19.71 & 44.18 \\
\hline $\begin{array}{l}\text { Overall mobility } \\
\text { (number of CEO's workplace changes) }\end{array}$ & 3.03 & 1.43 & 0.57 & 0.76 & 0.63 & 0.79 \\
\hline Post-degree titles & 1.16 & 1.23 & 0.64 & 1.08 & 1.40 & 1.58 \\
\hline Years in previous career & 8.92 & 4.00 & 14.86 & 6.27 & 11.79 & 5.93 \\
\hline
\end{tabular}

CEOs in the first cluster can be labelled "experienced CEOs". They show a higher number of different experiences as triad-managers. The results show that these CEOs have an overall number of triad-assignments equal to $5.89(\mathrm{sd}=2.27)$ and an overall mobility $(3.03 ; \mathrm{sd}=1.43)$ that is higher than the overall mobility of CEOs in the other clusters. They have been in more different structures than the others have, and they have been appointed by several political actors. The academic and teaching activities and the number of post-graduate degrees appear to be intermediate between the lowest (second cluster) and highest (third cluster) values. CEOs in this cluster are also those with a higher mean age $(60, s d=5)$ than both those in other clusters and the whole sample average.

CEOs in the second cluster can be labelled "business-like professionals" because, on average, their careers have the fewest triad assignments $(2.14$; $s \mathrm{~d}=1.29)$ and the highest mean number of 
managerial assignments (different from triad) among clusters, at $3.36(\mathrm{sd}=1.34)$. The results also indicate that they preferred to work in the private sector before joining public health-care (they have the highest average number of private managerial assignments, at 3.00). These statistics also suggest that these CEOs are in the early stages of their triad career in public health-care, especially if considering that they have the lowest average age (mean=55 years old, sd=5). These "business-like professionals" are those with a higher average duration of their previous career $(14.86, \mathrm{sd}=6.27)$. Matching the cluster analysis with the statistics of the professional categories (Table 4) to which CEOs belong, there is further confirmation of the statements about CEOs in the second cluster.

Table 4. CEOs previous career categories

\begin{tabular}{c|c|c|c|c}
\hline Cluster & $\begin{array}{c}\text { Administrative managers in } \\
\text { the clusters } \\
\text { (weights on the total of } \\
\text { administrative managers) }\end{array}$ & $\begin{array}{c}\text { Private-sector managers in } \\
\text { the clusters } \\
\text { (weights on the total of } \\
\text { private-sector managers) }\end{array}$ & $\begin{array}{c}\text { Physicians in the clusters } \\
\text { (weights on the total of } \\
\text { physicians) }\end{array}$ & $\begin{array}{c}\text { NA } \\
\text { (weights on the total } \\
\text { of NA) }\end{array}$ \\
\hline 1 & 24 & 0 & 36 & 1 \\
\hline 2 & $(42.11 \%)$ & $(0.000 \%)$ & $(38.71 \%)$ & $(33.33 \%)$ \\
\hline 3 & $(10.53 \%)$ & 6 & $(2.15 \%)$ & $(00.00 \%)$ \\
\hline $\begin{array}{c}\text { Total } \\
(\mathrm{n}=159)\end{array}$ & 27 & $(100.00 \%)$ & 55 & 2 \\
\hline
\end{tabular}

CEOs in the third cluster can be labelled as "experienced local directors". It is the largest cluster with a number of observations equal to 84 . This cluster is characterised by intermediate values of professional-linked variables among all the clusters and by the highest average number of publications (27.10; sd=60.89), teaching positions (3.01; $\mathrm{sd}=4.14)$ and conference attendances (19.71; sd=44.18).

The explanation for these results is two-fold. First, these CEOs are locally embedded, and, they present low average mobility $(0.60, \mathrm{sd}=0.78)$. Adding these characteristics to an average number of triad-assignments $(2.58, \mathrm{sd}=1.34$ ) and an average age that is equal to the whole sample's (58 years old, $s d=5)$, it can be noted how these CEOs preferred to take root in the places in which they work and that they have a slower career than CEOs in cluster 1 do. Second, by matching the cluster analysis results with the professional categories' distribution (Table 4), it can be noted that 65.48\% of the CEOs in cluster 3 are physicians (59.14\% physicians in the whole sample). Physicians are usually more involved in academic/teaching activities than are those in the other categories.

Finally, Table 5 shows the regional distribution of the selected CEOs by cross-referencing the groups gathered on the occurrence of the organizational arrangements in the regional procedures (see Table 2) and the results of the cluster analysis. 
Table 5. CEOs geographical distribution

\begin{tabular}{|c|c|c|c|c|c|}
\hline $\begin{array}{c}\text { Organizational } \\
\text { Arrangements } \\
\text { in appointment } \\
\text { procedures }\end{array}$ & Regions & Cluster 1 & Cluster 2 & Cluster 3 & TOTAL \\
\hline \multirow{5}{*}{$\begin{array}{l}\text { Group } 1 \\
\text { (High) }\end{array}$} & Emilia-Romagna & 4 & - & 8 & 12 \\
\hline & Liguria & 2 & - & 2 & 4 \\
\hline & Marche & 1 & - & 1 & 2 \\
\hline & Toscana & 4 & - & 3 & 7 \\
\hline & & 11 & 0 & 14 & 25 \\
\hline \multirow{8}{*}{$\begin{array}{l}\text { Group } 2 \\
\text { (Mid-high) }\end{array}$} & Campania & 6 & - & 8 & 14 \\
\hline & Friuli-V. Giulia & 3 & - & 2 & 5 \\
\hline & Lombardia & 8 & 4 & 16 & 28 \\
\hline & Piemonte & 12 & 2 & 4 & 18 \\
\hline & Sardegna & 2 & - & - & 2 \\
\hline & Sicilia & 3 & 2 & 9 & 14 \\
\hline & Trentino-A. Adige/Südtirol & 1 & 1 & - & 2 \\
\hline & & 35 & 9 & 39 & 83 \\
\hline $\begin{array}{l}\text { Group }(1+2) \\
\text { (Mid-High) }\end{array}$ & $\begin{array}{l}\text { Groups with mid-high } \\
\text { transparency in procedures }\end{array}$ & 46 & 9 & 53 & 108 \\
\hline \multirow{6}{*}{$\begin{array}{l}\text { Group } 3 \\
\text { (Mid-low) }\end{array}$} & Lazio & 6 & - & 7 & 13 \\
\hline & Molise & - & - & 1 & 1 \\
\hline & Puglia & 1 & 2 & 4 & 7 \\
\hline & Umbria & 1 & - & 2 & 3 \\
\hline & Veneto & 5 & 1 & 4 & 10 \\
\hline & & 13 & 3 & 18 & 34 \\
\hline \multirow{5}{*}{$\begin{array}{l}\text { Group } 4 \\
\text { (Low) }\end{array}$} & Abruzzo & - & 2 & 2 & 4 \\
\hline & Basilicata & - & - & 3 & 3 \\
\hline & Calabria & 2 & - & 7 & 9 \\
\hline & Valle d'Aosta & - & - & 1 & 1 \\
\hline & & 2 & 2 & 13 & 17 \\
\hline $\begin{array}{l}\text { Group }(3+4) \\
(\text { Mid-low) }\end{array}$ & $\begin{array}{l}\text { Groups with mid-low } \\
\text { transparency in procedures }\end{array}$ & 15 & 5 & 31 & 51 \\
\hline TOTAL & & 61 & 14 & 84 & $(n=) 159$ \\
\hline
\end{tabular}

Group 1 shows the highest occurrence of transparency and job definition and, at the same time, it merely contains "experienced CEOs" and "experienced local directors" which are distributed in a balanced way. Group 2 contains the highest number of observations. The related organizational arrangements medium-high were defined. In this case, the ratio between "experienced CEOs" and "experienced local directors" is quite balanced too. Finally, this group shows the highest incidence rate 
of "business-like professionals". In the remaining groups with a lower occurrence of transparency and job description there is no balance between "experienced CEOs" and "experienced local directors". Group 1 contains a prevailing number of "experienced local directors" as, in some cases, the Regions limit their selections to them and together with "business-like professionals" CEOs.

\section{Discussion}

Three different categories of Italian health-care CEOs represent the answer to the first research question. These three categories have significant differences in their professional characteristics and backgrounds, which represents the basis for the second research question. By comparing the three typologies, it is possible to rank them in the following order: 1) "experienced CEOs", 2) "experienced local directors", and 3) "business-like professionals". Experienced CEOs have the highest mobility of the clusters and the highest number of triad-assignments. Their experience gave them the opportunity to improve their skills (Sørensen, 1999) due to the high number of problems that they had to manage in different health-care structures (Higgins and Dillon, 2007). Furthermore, CEOs in the first cluster seem to have achieved the triad-position faster than CEOs in the second cluster did. On average, they spent less time in their previous careers $(8.92 ; s \mathrm{~d}=4)$ than "experienced local directors" $(11.79$; sd=5.93) did, and the average age difference between the clusters is approximately two years. Therefore, "experienced CEOs" can be ranked as the highest professional profile, and "experienced local directors" can be ranked as the second.

Further arguments can stress the idea of "experienced CEOs" as being the best profile particularly when compared with "experienced local directors". Even if "experienced local directors" seem to have a better educational background and the highest number of publications and teaching experiences, which is, of course, useful in terms of expected skills, in profiling the "best" CEO the study gives particular emphasis to the characteristic drawn from the professional career. A significant difference among local and not-local CEO supports the idea: it is about the nature of the competence and the social/professional network they could bring.

Regarding the competences, it has been highlighted how the inter-organizational mobility and a major number of assignments can bring a wider repertoire of professional knowledge accumulated over the time (Mascia and Piconi, 2013). Organizations also receive benefits from mobility because they gain access to new organizational skills that belong to this kind of CEOs (Sørensen, 1999). This does not exclude relevant professional competences in the case of local CEOs but they will be not as varied as for the others. At the same time, with respect to the social/professional network, it has been shown how a high degree of mobility enhances the number of relations but distances the managers from stable networks that are, on the contrary, facilitated by a stable local career (Collin, 1986). In the idea, the high risk of patronage is likely to occur in the second hypothesis. A local career could mean a stable network (particularly in case of former physicians) to turn into Presidents' political support, and in such a scenario, the appointment could mean a sort of reward 
for the political support. Following this line, the regional Presidents' choices of "experienced local directors" could represent an act beyond the simple dichotomy between political and professional appointments, since they could satisfy at the same time the requirements of both professional skill and "political support". In this sense, this is in line with Kopechy et al. (2016) when they show that local politicians prefer to select appointees who are characterised by political and personal loyalty as well as professional competence. Finally, "Business-like professionals" can be placed in the third position because of their low experience compared to the other two profiles. Moreover, "business-like professionals" constitute a very small cluster when comparing their dimension (14 observations) with "experienced CEOs" (61 observations) and "experienced local directors" (84 observations). Therefore, "business-like professionals" show the lowest professional background and are the residual choice of the regional government.

The most relevant criterion in appointing choices seems to be the managerial experience of CEOs. Political decision makers have been shown to prefer two of the three profiles that were defined: (i) "experienced CEOs", and (ii) "experienced local directors". The comparison between these typologies should be enriched by considering the reference career area. The out-of-region mobility ratio indicates that there is a small difference between "experienced CEOs" (0.06; $s d=0.14)$ and experienced local directors $(0.03$; $s d=0.10)$. Again, "experienced CEOs" prevail in the comparison.

The overall out-of-region mobility is also very small $(0.05, \mathrm{sd}=0.14)$. These low statistics suggest that CEOs tend to stay in the mode-region. Considering the whole sample, only $15 \%$ of the CEOs had at least one triad-assignment outside his/her mode-region. Further, $67 \%$ of these CEOs are "experienced CEOs", and "experienced local directors" represent $21 \%$ of the CEOs with at least one out-of-region triad-assignment. This confirms the classification of CEOs' professional profiles and suggests that "experienced CEOs" are more attractive for political decision-makers.

"Experienced CEOs" have been identified as the best profile. Nevertheless, only 38\% of CEOs in the sample belong to the first cluster. In their recent study, Mascia and Piconi (2013) showed that higher experience and professional skills of health-care CEOs are related to higher levels of performance. Our study shows that the selection system leads to these high-skilled CEOs being identified in the minority of cases.

The third research question is consequential to the others: the CEOs distribution over the four groups of regions according to the occurrence of the organizational arrangements was considered.

It seems that when the organizational arrangements are better employed, they have some effect in the overall public appointment process: they totally exclude the selection of "businesslike professionals" that were ranked as the lowest CEOs, and as the residual choice of the regional government. On the contrary, when there is any kind of organizational arrangements or they are wrongly employed, "experienced local directors" increases, while "experienced CEOs" decreases. While these findings clearly need to be further explored, they support the idea that a choice in favour of the experienced local directors is at a greater risk of patronage as well as a process without any organizational arrangement is a tool of patronage. 


\section{Conclusions}

The question of whether the CEO's appointment procedure could be an effective way to attract highly skilled management or whether it could turn into a high patronage tool with the consequence of enhancing clientelism does not have a homogeneous answer. The overall results of the selection system of CEOs in the health-care firms in Italy lead to suboptimal appointments: the appointment procedure shows differences both in terms of the typologies of $\mathrm{CEO}$ s and in terms of organizational arrangements in attracting highly competitive managers. On the one hand, the greater number of experienced local directors could show that Presidents' choices are mainly a balance between professional skills and political reliability. On the other hand, the study highlights how the best procedures, when considering the organizational arrangements, allow to select the highest profiles of CEOs, even if only $38 \%$ of the whole samples. As noted above, the way in which public appointment are locally managed could help control how the local institutions contribute to implement NPM, when considering the national regulations and the lack of specific conditions for appointing CEOs. Some Presidents have integrated the national regulations with clear standard on a regional basis. When the local procedures provide essential organizational arrangements, they are at the same time the expression of autonomy and accountability. This seems to be the best way to cope with the Reform Law of the 1990s (59/1997 law as amended).

As stated, even if the findings need to be further explored, three implications can be clearly highlighted.

1. In terms of policy implications, the study confirms the importance of putting the procedures for public appointments more clearly on the public agenda and of ensuring the transparency of all of the eligible positions.

2. Organizational arrangements can help to use public appointments as a tool of good governance rather than as a tool of patronage.

3. The Presidents' direct choice in terms of selection should be enforced by their direct responsibility in terms of CEOs' performance and results. In other words, when a CEO fails in managing his/ her local health-care firm, then it should reflect on the President who made the appointment.

As a preliminary study, the research needs to consider other elements that could be taken into account during the selection, such as the organizational size of the health firms, the number of units, etc. Furthermore, research should investigate how and to what extent political elements affect the final phase of the selection process. In this perspective, future studies may provide further and more refined frameworks of analysis and apply them across different contexts. 


\section{References}

Anessi-Pessina, E. \& Cantù, E. (2006). Whither managerialism in the Italian national healthservice?, The International journal of health planning and management, 21(4): 327-355. DOI: https://doi.org/10.1002/hpm.861

Baroni, D. (2004). Enti locali e aziende di servizi pubblici: assetti e processi di governance. Milano: Giuffrè editore.

Cañibano, C. \& Bozeman, B. (2009). Curriculum vitae method in science policy and research evaluation: the state-ofthe-art, Research Evaluation, 18(2): 86-94. DOI: https://doi.org/10.3152/095820209x441754

Christensen, T., Lægreid, P. \& Wise, L.R. (2000). Active Administrative Policy: Presumptions and Practice: the Case of Norway, Sweden and the USA. Bergen: LOS Centre, working paper 0015.

Collin, (1986). Career Development: The Significance of the Subjective Career, Personnel Review, 15(2):22-28. DOI: https://doi.org/10.1108/eb055535

Dent, M. (2005). Post-new public management in public sector hospitals? The UK, Germany and Italy, Policy and Politics, 33(4): 623-636. DOI: https://doi.org/10.1332/030557305774329208

Henderson, A., Jeffery, C., Wincott, D. \& Wyn Jones, R. (2013). Reflections on the "Devolution Paradox": A comparative examination of multilevel citizenship, Regional Studies, 47(3): 303-322. DOI: https://doi.org/10.1080/003434 04.2013 .768764

Higgins, M.C. \& Dillon, J.R. (2007). Career patterns and organizational career. In: H. Gunz \& M. Peiperl (Eds.), Handbook of Career Studies, pp. 422-436. Thousand Oaks, CA: Sage Publications. DOI: https://doi. org/10.4135/9781412976107. n21.

Hood, C. (1991). A public management for all seasons?, Public administration, 69(1): 3-19. DOI: https://doi. org/10.1111/j.1467-9299.1991.tb00779.x

Hood, C. (2000). Paradoxes of public-sector managerialism, old public management and public service bargains, International public management journal, 3(1): 1-22. DOI: https://doi.org/10.1016/s1096-7494(00)00032-5

Hood, C. \& Peters, G. (2004). The middle aging of new public management: into the age of paradox?, Journal of public administration research and theory, 14(3): 267-282. DOI: https://doi.org/10.1093/jopart/muh019

InCiSE (2017). The International Civil Service Effectiveness (InCiSE) Index, Report 2017.

Kopecký, P., Meyer Sahling, J. H., Panizza, F., Scherlis, G., Schuster, C. \& Spirova, M. (2016). Party patronage in contemporary democracies: Results from an expert survey in 22 countries from five regions, European Journal of Political Research, 55(2): 416-431. DOI: https://doi.org/10.1111/1475-6765.12135

Jommi, C., Cantù, E. \& Anessi-Pessina, E. (2001). New funding arrangements in the Italian National Health Service, The International journal of health planning and management, 16(4):347-368. DOI: https://doi.org/10.1002/hpm.641

Maor, M. (1999). The paradox of managerialism. Public Administration Review, (15): 5-18. DOI: https://doi. org/10.2307/977475

Mascia, D. \& Piconi, I. (2013). Career histories and managerial performance of health-care chief executive officers: An empirical study in the Italian National Health Service, Health-care management review, 38(1): 71-80. DOI: https://doi.org/10.1097/hmr.0b013e31823dc85b

Mattei, P. (2006). The enterprise formula, New Public Management and the Italian Health-care System: Remedy or contagion?, Public Administration, 84(4): 1007-1027. DOI: https://doi.org/10.1097/hmr.0b013e31823dc85b.

Page, E. \& Wright, V. (Eds.) (1999). Bureaucratic elites in Western European states. Oxford University Press. DOI: https:// doi.org/10.1093/0198294468.001.0001

Putnam, R.D. (1993). The prosperous community, The American prospect, 4(13): 35-42.

Sandström, U. (2009). Combining curriculum vitae and bibliometric analysis: mobility, gender and research performance, Research Evaluation, 18(2): 135-142. DOI: https://doi.org/10.3152/095820209X441790 
Saraceno, C. \& Negri, N. (1994). The changing Italian welfare state, Journal of European social policy, 4(1): 19-34. DOI: https://doi.org/10.1177/095892879400400102

Sancino, A., Sicilia, M. \& Grossi, G. (2017). Between patronage and good governance: Organizational arrangements in (local) public appointment processes, International Review of Administrative Sciences 0(0): 1-18.

Simonet, D. (2008). The New Public Management theory and European health-care reforms, Canadian public administration, 51(4): 617-635.21. DOI: https://doi.org/10.1111/j.1754-7121.2008.00044.x

Sørensen, J.B. (1999). Executive migration and interorganizational competition, Social Science Research, 28: 289-315. DOI: https://doi.org/10.1006/ssre.1999.0650

Sundell, A. (2012). What is the Best Way to Recruit Public Servants, QoG Working paper series, 2012(7). University of Gothenburg.

Tediosi, F., Gabriele, S. \& Longo, F. (2009). Governing decentralization in health-care under tough budget constraint: what can we learn from the Italian experience?, Health Policy, 90(2): 303-312. DOI: https://doi.org/10.1016/j. healthpol.2008.10.012

Ward, J.H. Jr. (1963). Hierarchical Grouping to Optimize an Objective Function, Journal of the American Statistical Association, 58: 236-244. DOI: https://doi.org/10.2307/2282967. 


\section{Appendix}

Table A. CEOs' final degree marks

\begin{tabular}{c|c|c|c|c|c}
\hline Degree Final Mark & n & Cluster 1 & Cluster 2 & Cluster 3 & Total \\
\hline 87 & 1 & 1 & - & - & $1(0.63 \%)$ \\
\hline 95 & 1 & - & - & 1 & $1(0.63 \%)$ \\
\hline 100 & 4 & - & 2 & 2 & $4(2.51 \%)$ \\
\hline 103 & 3 & 1 & - & 3 & $3(1.90 \%)$ \\
\hline 104 & 4 & - & 2 & 2 & $4(2.51 \%)$ \\
\hline 105 & 5 & 2 & - & 3 & $5(3.14 \%)$ \\
\hline 106 & 1 & 1 & - & - & $1(0.63 \%)$ \\
\hline 107 & 2 & 2 & - & - & $2(1.26 \%)$ \\
\hline 108 & 1 & 1 & - & - & $1(0.63 \%)$ \\
\hline 110 & 20 & 6 & - & 14 & $20(12.58 \%)$ \\
\hline $110 \mathrm{~L}$ & 34 & 8 & 3 & 23 & $34(21.38 \%)$ \\
\hline NA & 83 & 39 & 7 & 37 & $83(52.20 \%)$ \\
\hline Total & 159 & 61 & 14 & 84 & \\
\hline
\end{tabular}

Table B. Gender and age in the whole sample and in the clusters

\begin{tabular}{|c|c|c|c|c|c|c|c|c|c|c|c|c|c|c|c|}
\hline \multicolumn{4}{|c|}{ Whole Sample (n=159) } & \multicolumn{4}{|c|}{ Cluster $1(n=61)$} & \multicolumn{4}{|c|}{ Cluster $2(n=14)$} & \multicolumn{4}{|c|}{ Cluster $3(n=84)$} \\
\hline \multicolumn{2}{|c|}{ Gender } & \multicolumn{2}{|c|}{ Age } & \multicolumn{2}{|c|}{ Gender } & \multicolumn{2}{|c|}{ Age } & \multicolumn{2}{|c|}{ Gender } & \multicolumn{2}{|c|}{ Age } & \multicolumn{2}{|c|}{ Gender } & \multicolumn{2}{|c|}{ Age } \\
\hline Male & Female & Mean & sd & Male & Female & Mean & sd & Male & Female & Mean & sd & Male & Female & Mean & sd \\
\hline $84.28 \%$ & $15.72 \%$ & 58 & 5 & $\begin{array}{c}52 \\
(85.25 \%)\end{array}$ & $\begin{array}{c}9 \\
(14.75 \%)\end{array}$ & 60 & 5 & $\begin{array}{c}13 \\
(92.86 \%)\end{array}$ & $\begin{array}{c}1 \\
(7.14 \%)\end{array}$ & 55 & 5 & $\begin{array}{c}69 \\
(82.14 \%)\end{array}$ & $\mid \begin{array}{c}15 \\
(17.86 \%)\end{array}$ & 58 & 5 \\
\hline
\end{tabular}

Note: Gender distribution of the observations over the clusters. Percentages in parenthesis refer to the weight of the frequencies over the single cluster (e.g. in cluster 1 we have 52 men that correspond to $85.25 \%$ of cluster 1 ). 